\title{
Evaluation of cloned cells, animal model, and ATRA sensitivity of human testicular yolk sac tumor
}

\author{
Junfeng Zhao', Congde Chen", Haochuan Zhang ${ }^{1}$, Jinhui Shen ${ }^{1}$, Hua Zhang ${ }^{1}$, Xiaokun Lin', Le Qin', \\ Xiaozhou Bao', Jie Lin', Wenqiang Lu', Xiangdong Wang ${ }^{2}$ and Xiaoming Chen ${ }^{1,2,3^{*}}$
}

\begin{abstract}
The testicular yolk sac tumor (TYST) is the most common neoplasm originated from germ cells differentiated abnormally, a major part of pediatric malignant testicular tumors. The present study aimed at developing and validating the in vitro and vivo models of TYST and evaluating the sensitivity of TYST to treatments, by cloning human TYST cells and investigating the histology, ultra-structure, growth kinetics and expression of specific proteins of cloned cells. We found biological characteristics of cloned TYST cells were similar to the yolk sac tumor and differentiated from the columnar to glandular-like or goblet cells-like cells. Chromosomes for tumor identification in each passage met nature of the primary tumor. TYST cells were more sensitive to all-trans-retinoic acid which had significantly inhibitory effects on cell proliferation. Cisplatin induced apoptosis of TYST cells through the activation of p53 expression and down-regulation of Bcl- expression. Thus, we believe that cloned TYST cells and the animal model developed here are useful to understand the molecular mechanism of TYST cells and develop potential therapies for human TYST.
\end{abstract}

Keywords: Testicular yolk sac tumor, Human, Clone, Model, ATRA, Cisplatin

\section{Introduction}

The testicular yolk sac tumor (TYST) is the most common neoplasm originated from germ cells differentiated abnormally [1], while germ cell tumors in the testis account for approximately $60-75 \%$ of pediatric malignant testicular tumors. The yolk sac tumor as endodermal sinus tumor is a common malignant tumor accounting for $1-2 \%$ of cancers in men and one of the most common types of cancer in young men between 15-35 ages. Of them, the TYST mainly occurs in neonates and infants, different from adolescences or adults who composed of multiple germ cells and having own biological characters [2].

The TYST is still a highly malignant neoplasm with poor prognosis, increased resistance to chemotherapy, recurrence after initial chemotherapy or surgery, and the side effects of chemotherapeutics, even though the

\footnotetext{
*Correspondence: cxm@wzmc.net

'Department of Pediatric Surgery, the Second Hospital, Wenzhou Medical

College, Wenzhou, China

Full list of author information is available at the end of the article
}

survival rate of patients with TYST was improved after surgical resection or platinum-based combination chemotherapy, e.g. cisplatin, etoposide and bleomycin [3]. The regulation of cell differentiation from immature malignant tumor cells to mature was suggested as a potential therapy for tumors [4]. Conventional radiotherapy and/or chemotherapy were found to suppress the bone marrow and immune function through influencing cell phenotypes [5]. The cell apoptosis is closely related with the tumorigeness, tumor development and insensitivity of chemotherapy/radiation therapy [6].

There are limited studies on human TYSTs, although YST has been studies in cells from male murine embryonal carcinoma in vitro [7] and ovarian YST cell lines [8]. The present studies aimed at establishing the animal model of TYST and the human TYST cell line and evaluating the characteristics of the disease and bio-function of human TYST cells. The present study evaluated the role of ATRA as an inducer of differentiation in a variety of tumor cells in the growth TYST cell lines in vitro and explored the molecular mechanism of TYST cell 
proliferation. Effects of cisplatin on TYST cell apoptosis and the expression of P53 and Bcl-2 genes were furthermore investigated.

\section{Materials and methods TYST and sampling}

TYST tissues were sampled children with TYST, aging about 2-3 years-old, during the testicular surgery, without any radiotherapy or chemotherapy. The study protocol and informed consent of the sampling for scientific research were approved by The Ethical Committee of Clinical Research of Second Affiliated Hospital of Wenzhou Medical College. Informed written consents were approved from guardians on the behalf of the children participants involved in the study. Tumors with diameters about 50-70 $\mathrm{mm}$ and without the encapsulation were severely adhered with the surrounding tissues. Plasma levels of alpha-fetoprotein were above $1200 \mathrm{ng} /$ $\mathrm{ml}$, corresponded with the normal reference value of 0-7 $\mathrm{ng} / \mathrm{ml}$. TYST samples were positive in immunohistochemical staining against cytokeratins and alphafetoprotein.

\section{A xenograft tumor model}

Male BALB/C mice with the autosomal recessive nude gene in homozygous $(\mathrm{nu} / \mathrm{nu})$, aging four weeks, were purchased from Shanghai Experimental Animal Center of Chinese Academy of Sciences. Mice were housed and maintained in individual ventilation cabinets under specific pathogen-free conditions with constant temperature at $24^{\circ} \mathrm{C}$. Animal studies were approved by the local ethical committee for animal care according to international guidelines and regulations for use and care of animals. Human tumor specimen from the surgery was washed immediately and sliced into near $1 \mathrm{~mm}^{3}$ masses under sterile conditions. Each piece of tumor mass was implanted hypodermically into the unilateral inguinal region in mice. Tumors growth was observed periodically and mice were terminated until the tumor grew to $2-3 \mathrm{~cm}$ in diameter. Tumors were exteriorized and implanted in new mice as described, and then perpetuated in mice by consecutive passages from the primary tumor. This study was carried out in strict accordance with the recommendations in the Guide for the Care and Use of Laboratory Animals of the National Institutes of Health. The protocol was approved by the Ethical Committee on Animal Experiments of the Wenzhou Medical College. All surgery was performed under anesthesia of sodium pentobarbital to minimize suffering.

\section{Measure of tumor growth}

The latent period and growth rate of tumor were recorded daily. Volumes and exponential function of tumors were measured weekly from the day when tumors reached $3 \mathrm{~mm}$ in diameter. Volume of tumors $(\mathrm{Vt})$ was calculated in the formula: $\mathrm{Vt}=\pi(\mathrm{b} 2 \times \mathrm{a}) / 6(\mathrm{~b}$ and a represent the minimal and maximal diameter in millimeters, respectively) and exponential function (K) was calculated as growth rate: $\mathrm{K}=(\mathrm{InVt}-\mathrm{InV0})$, and then doubling time: $\mathrm{Td}=\mathrm{In} 2 / \mathrm{K}$.

\section{TYST morphologies}

Tumors were obtained from surgical resection, fixed in $10 \%$ formalin, embedded with paraffin, and sectioned in a thickness of $4 \mathrm{um}$. Slices were then de-paraffinized, rehydrated, and finally stained with hematoxylin and eosin. The tumor morphology was analyzed and observed under light microscope. For ultrastructural analysis, tumors were cut into small pieces about 1 $\mathrm{mm}^{3}$, immersed and fixed in a solution of $4 \%$ glutaraldehyde $\left(\mathrm{pH} 7.3,4^{\circ} \mathrm{C}\right)$. Fixed samples were washed in phosphate buffer twice and then post-fixed in 1\% osmium tetroxide (Polysciences Inc., New Orleans, LA, USA) for $1 \mathrm{hr}$. Samples were then rinsed extensively in distilled water, dehydrated in a graded series of ethanol, embedded in Eponate 812 resin (Ted Pella Inc., Redding, USA), and dried by heat with a graded temperature. Sections of $50 \mathrm{~nm}$ were then cut with a Leica Ultracut UCT ultramicrotome (Leica Microsystems Inc, LKB-II, Germany), stained with 3\% solution of uranyl acetate and lead citrate, and mounted on mesh grids. Digital pictures $(2048 \times 2048$ pixels, $4 \mathrm{MB}$, and uncompressed grayscale Tiff files) were obtained using a high resolution digital camera MegaViewIII (SIS ${ }^{\circledR}$ ) connected to the TEM, and observed at electron microscope with an acceleration voltage of $80 \mathrm{kV}$, in JEOL JEM-1230 (Japan).

\section{Immunohistochemistry}

TYST Tumors were fixed in formalin for approximately $10 \mathrm{hrs}$, embedded in paraffin overnight in a routine fashion, and cut into sections at the thickness of $4 \mu \mathrm{m}$. Sections were subsequently boiled for 10 minutes in 10 $\mathrm{mM}$ citrate ( $\mathrm{pH}$ 6.0), after being dewaxed and incubated in methanol containing $0.3 \% \mathrm{H}_{2} \mathrm{O}_{2}$ for 15 minutes. Sections were digested with $0.25 \%$ pepsin (Sigma) dissolved in $0.1 \mathrm{M} \mathrm{HCl}$ for 15 minutes at $37^{\circ} \mathrm{C}$, blocked for 30 minutes in PBS containing 5\% normal mouse serum (Jackson Immunoresearch, Newmarket, UK), and then incubated with antibodies again alpha-fetoprotein (AFP, goat anti-mouse alpha-fetoprotein polyclonal antibody; R\&D Systems, Minneapolis, USA), placental alkaline phosphatase (PLAP, anti-placental alkaline phosphatase antibody, Abcam, Cambridge, UK), or cytokeratins (CK, mouse anti-mouse cytokeratin 10 monoclonal antibody, unconjugated, clone Spm262; Thermo Fisher Scientific, Rockford, IL, USA) for 2 hours, while HRP-conjugated 
secondary antibodies for 30 minutes, both at room temperature. TYST sections were stained using 3,3'-diaminobenzidine and alternatively counterstained with haematoxylin. The concentrations of primary antibodies were used at 1:100. TYST sections were observed and photographed under an inverted Olympus phase contrast microscope equipped with a digital camera (Olympus dp71, Japan). For the analysis of positive cellular numbers (PCN) and the optical density (OD), total 20 hotspot fields were captured for each section in viable zones at $\times 400$ using a camera and analyzed by imagepro plus 6.0 software. Semi-quantitative analyses of immunohistochemical staining were performed as the formula of expression values $(\mathrm{EP}):=\mathrm{PCN} \times \mathrm{OD}$.

\section{Chromosomes analysis}

Fresh TYST samples were obtained, washed with PBS twice, sliced into small particles, and then put into culture medium (RPMI 1640, L-glutamine $2 \mathrm{mM}$, penicillin 100 units/ml, streptomycin $100 \mathrm{mg} / \mathrm{ml}$, colcemid $0.1 \mathrm{pg} /$ $\mathrm{ml})$ without serum. These particles were put into colchicine and incubated in the water bath at $37^{\circ} \mathrm{C}$ for $1 \mathrm{~h}$. Tumor cells were centrifuged, fixed, and detected in Gbanding. Chromosomes were counterstained and reverse banded by mounting the slides in Citifluor antifade AFl (Citifluor Ltd) containing $2.5 \mu \mathrm{g} / \mathrm{ml}$ of DAPI and $0.5 \mu \mathrm{g} /$ $\mathrm{ml}$ of propidium iodide, as described in previous studies [9]. Hybridised slides were assessed using a Nikon Optiphot fluorescence microscope with a $\times 100$. Images were recorded as grey levels at two detectors (detector 1, 500 to $560 \mathrm{~nm}$; detector $2<600 \mathrm{~nm}$ ) of an MRC 600 confocal scanning head (Biorad) and displayed in a pseudo-color (FITC fluorescence in green, PI fluorescence in red). The band location of FITC signal was determined by toggling the FITC signal to allow the banding pattern beneath the signal.

\section{Primary culture of TYST cells and establishment of cell line}

TYST tissues were harvested, immediately washed by $\mathrm{D}$ Hank's solution $\left(\mathrm{NaCl} 8.0 \mathrm{~g}, \mathrm{KCl} 0.2 \mathrm{~g}, \mathrm{Na}_{2} \mathrm{HPO}_{4} \cdot \mathrm{H}_{2} \mathrm{O}\right.$ $1.56 \mathrm{~g}, \mathrm{KH}_{2} \mathrm{PO}_{4} 0.2 \mathrm{~g}$ in $1 \mathrm{~L}$ distilled water) in order to clean up blood and mucus in surface, and then sliced into $1 \mathrm{~mm}^{3}$ pieces. Sliced tissues incubated in Dulbecco's modified Eagle medium (GibcoBRL, Grand Island, NY, USA) solution containing $20 \%$ fetal calf serum at $37^{\circ} \mathrm{C}$. The first generation of cells was passed when cells grew to cover the $80 \%$ bottom of the culture bottle in 14 days, and the second passage in 8 days. From the third generation of cells, the average passage time was 3 to 4 days until 25 generation and cells grew stably and kept the primary characteristics. Cells from the 8th generation were used in the study and the survival rate of recovery cells from freezing reached about $80 \%$ and their morphologies were observed under inverted microscope, light microscope and electron microscope, respectively.

\section{Bio-function measurement}

Cell growth curve was drawn by counting and recording cell density of three holes, of which each was operated with 3 times interval 24 hours during days 1-8. Cells were diluted at the density of $2 \times 10^{4}$ per $\mathrm{ml}$ and inoculated into 24-well plate. The single cell suspension was made and cell doubling time was monitored. Cytogenetic analysis was performed in TYST cells in the logarithmic growth phase, after cells were treated with trypsin, fixed with methanol-acetic acid solution, and stained with trypsin-Giemsa. About 100 cells in metaphase and the number of chromosomes and its modes were accounted [10], after then pictures were captured by Applied Imaging Software with G-banding analysis. The expression of AFP and beta-subunit human chorionic gonadotrophin ( $\beta$-hCG) was measured by immunocytochemical staining according to the manufacture recommendation.

\section{DNA ploidy analysis}

Cellular DNA ploidy and cycle were detected by flow cytometry, as described previously [11]. Briefly, DNA ploidy was analyzed after the cell sorting, after the flow cytometry was calibrated with fluorescent DNA-Check Beads (Coulter) to obtain a percentage half peak coefficient of variation (\%HPCV). Histograms were recorded for a minimum of 10,000 nuclei, according to the guideline criteria drawn up in the DNA Cytometry Consensus Conference [12]. The exclusive criteria were the coefficient of variation greater than $8 \%$ or background debris constituting more than $20 \%$. DNA diploidy was defined by the presence of a single G0/G1 peak to a histogram. A tumor was considered as aneupoid if a histogram had two separate G0/G1 peaks. The DNA index was calculated from the ratio of the model channel numbers of aneuploid peaks to the modal channel numbers of the diploid peak. Intratumoral DNA heterogeneity was defined by the presence of both DNA diploidy and aneuploidy with a tumor, or by the presence of multiple stem lines in aneuploid patterns. DNA histograms were assessed using MultiCycle software version 2.5 (Coulter) to determine the SPF. A polynomial modeling system was used for cell cycle analysis.

\section{Cloning procedure}

Cells at the 26th passage were cultured in soft agar and the rate of cell clones formation was tested. Briefly, cells were cultured in the medium containing high glucose Dulbecco's modified Eagle medium supplemented with $10 \%$ fetal bovine serum (Hyclone, Utah, USA). Two days 
after cell passage, the medium was transferred into a sterile tube (Corning Incorporated, Corning, NY, USA), centrifuged at $2000 \mathrm{rpm}$ for $10 \mathrm{~min}$. Cells grew to approximately $80 \%$ confluence, and the culture flask was placed in 4 refrigerator for $4 \mathrm{~h}$ to synchronize the cells, followed by incubation overnight. The single cell suspension was prepared after trypsinization $(2.5 \mathrm{~g} / \mathrm{L}$ trypsin, Difco, prepared in $\mathrm{Ca}^{2+}$ and $\mathrm{Mg}^{2+}$ free Hanks solution d-Hanks). The cell viability was confirmed by trypan blue exclusion, and cloning procedure was performed using the limited dilution method [6]. The cloned cells were preserved in culture medium containing $100 \mathrm{~g} / \mathrm{L}$ dimethyl sulfoxide (DMSO, Sigma Chemical Co, St Louis, MO, USA), and stored in liquid nitrogen till used for in vivo screening.

\section{Role of retinoic acid}

Cloned TYST - cells were randomly divided into five groups ( $n=10 /$ group) treated with vehicle (group 1 ) or ATRA at concentrations of $0.01,0.1,1.0$ or $5.0 \mathrm{uM}$ (groups 2-5). ATRA was solved in ethanol at the start and diluted with PBS at the final concentration of $0.1 \%$ as vehicle. Cells were seeded in 6-well culture plates at $2 \times 10^{4}$ for 24 hours and the original medium was replaced by the different concentrations of ATRA solution. Cells growth was monitored under inverted microscope daily for 7 days. Inhibitory effects of ATRA on TYST cell proliferation were detected by MTT assay at 24, 48 and 72 hours, respectively. The absorbency was measured with the colorimetric microplate reader at the wavelength of $570 \mathrm{~nm}$. The inhibitory rate was calculated as the following formula: $(\%)=(1$ - experimental control group OD/blank control group OD) $\times 100 \%$. The expression of retinoic acid receptor $\beta$ (RAR- $\beta$ ) in cells was measured by RT-PCR, after total RNAs were extracted in each experimental group, according to manufacture's protocol. The synthesis of cDNAs was followed by reverse transcriptase kit protocol. Human RAR $-\beta$ primer sequences include: forward primer 5'GAGGACTGGGATGCCGAGAA-3' and reverse primer 5'-TTGACCCAAACCGAATGGC-3'; and human $\beta$ actin: forward primer 5'-TCGACAGCTCCGGCAT-3' and reverse primer 5'-AAGGTGTGGTGCCAGATTTTC-3'. Twenty-two cycles of amplification with denaturation at $94^{\circ} \mathrm{C}$, annealing at $60^{\circ} \mathrm{C}$ and extension at $72^{\circ} \mathrm{C}$ for $60 \mathrm{~s}$ each, were carried out after the initial predenaturation at $95^{\circ} \mathrm{C}$ for $5 \mathrm{~min}$. The relative expression of targeted mRNA = the product of targeted mRNA with the volume of gary/the product of $\beta$-actin with the volume of gray.

\section{Role of cisplatin}

Cloned TYS cells at the 6th passage were treated with cisplatin at the concentration of $2 \mu \mathrm{g} / \mathrm{ml}$ for $12,24,48$ and 72 hours, respectively. Acridine Orange/Ethidium Bromide $(\mathrm{AO} / \mathrm{EB})$ staining fluid at the concentration of $100 \mathrm{mg} / \mathrm{L}$ was added into 96-wells at the volume of 20 $\mu 1$. Cells were incubated at dark for $20 \mathrm{~min}$ and observed under fluorescence microscope. Cell apoptosis was analyzed with terminal deoxynucleotidyl transferasemediated biotin-dUTP nick end labeling (TUNEL) staining (Merck). Briefly, specimens were incubated with proteinase $\mathrm{K}$ at $20 \mu \mathrm{g} / \mathrm{ml}$ for $15 \mathrm{~min}$ at room temperature and washed with PBS for 5 min thrice. Sections were blocked with $3 \%$ bovine serum albumin and $20 \%$ fetal calf serum solution for $30 \mathrm{~min}$, and incubated with TUNEL reaction mixture of TdT and dUTP (1:9) at $37^{\circ}$ $\mathrm{C}$ for $1 \mathrm{~h}$. Finally, samples were stained with DAB under control of microscope, and counterstained with hematoxylin for $1 \mathrm{~min}$. Total five fields were captured for each section under microscope. The apoptotic index $(\mathrm{AI})=$ the positive cell numbers/total cell numbers Expression of AFP, P53 and Bcl-2 proteins was detected with immunohistochemical staining. Mouse monoclonal antibodies of AFP, P53 and Bcl-2 were diluted with 1:100. Positive cellular numbers, optical density, and total ten fields captured for each section in viable tissue zones using a camera $(\times 400$, Nikon Digital Sight DS-L2, Japan), were analyzed by Image-pro plus6.0 software, respectively. The semi-quantitative $=$ optical density $\times$ cellular numbers.

\section{Statistical analysis}

Data are presented as means \pm standard deviation. All experiments were performed twice and 3-5 animals in a group were randomly allocated into each study. After statistical analysis demonstrated no significance between studies, the results from the same group $(n=6-10)$ were pooled. The difference between groups and time points was calculated using the unpaired, two-tailed Student t-test after the analysis of one-way ANOVA. Inhibitory effects (\%) were calculated as the formula: inhibitory rate $(\%)=[$ (values of MMT density in different time points treated with different concentrations of inhibitors - values of MMT density in different time points treated with vehicle) - values of MMT density in different time points treated with vehicle] $\times 100$. A pvalue of less than 0.05 was considered significant.

\section{Results}

Average volumes of tumor driven from the primary generation, the first generation and the second generation of TYST cells were increased, as shown in Figure 1A. Tumor cell volumes of three generations started to show different from the 10 cycles. Consecutive transplantation of total 7 generations into the subcutaneous inguinal region of nude mice was performed during 15 months. The rate of tumor formations was 20, 40 and 


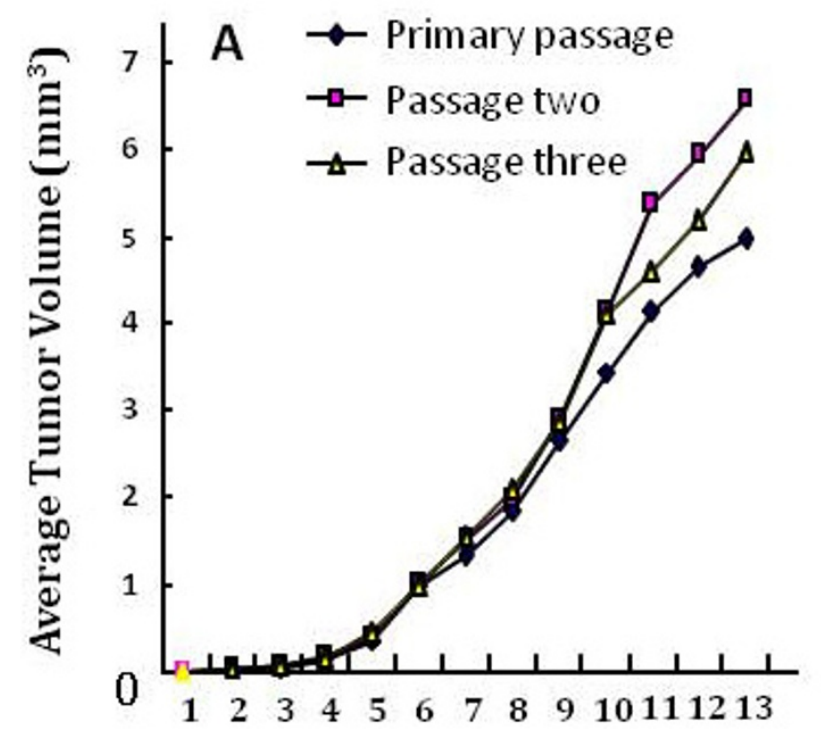

C

Cell cycles

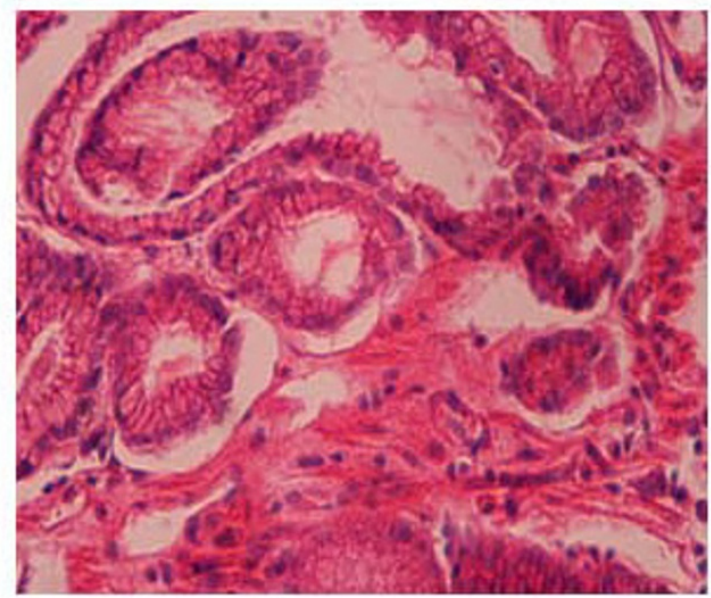

B

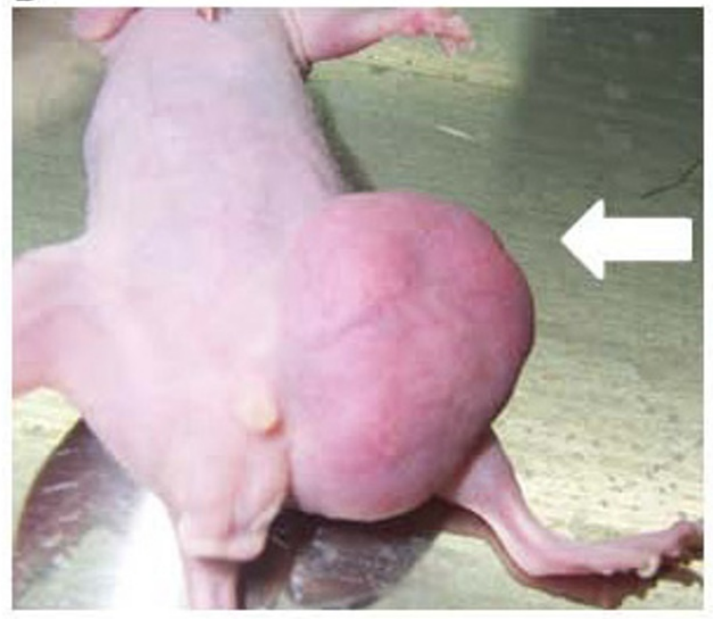

D

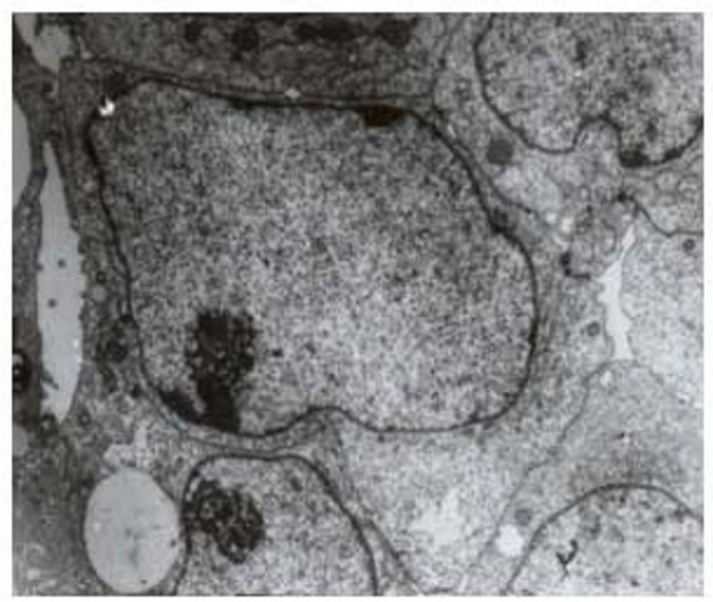

Figure 1 Average volumes of tumor driven from the primary generation, the first generation and the second generation of testicular yolk sac tumor (TYST) cells were compared with the number of cell cycles (A). The tumor was formed from the generation four of TYST cells and on after the subcutaneous transplantation (B). Histogram of tumor formed from cloned TYST cells stained with HE (C, $\times 400)$. Ultrastructure of cloned TYST cells with basement membrane materials, oval and enlargement nuclei, and glandular-like structures between cells $(\mathbf{D}, \times 5000)$.

$65 \%$ in the generations one, two and three, respectively, and reached $100 \%$ from the generation four and on after the subcutaneous transplantation (Figure 1B). The average period of tumor formation was 32 days and the maximal time of tumor growth was 192 days in mice. Tumor could grow to about $32 \times 28 \mathrm{~mm}^{3}$ in volume, of which some had the ulceration and necrosis on the surface of TYST and lead to cachexia in nude mice. All tumors represented the substantial neoplasm without cystic or mixed ones.

Tumors and internal organs, like liver and lungs, were harvested and stained immediately after tumor-bearing mice were sacrificed (Figure 1C). TYST cells had enlarged volume, obvious heteromorphism, large nucleolus with stained deeply and disordered, abundant cytoplasm with pale staining. The nuclei appeared round or 
oval, arranged like the glomerular structure and loose mesh-like structure. Some of TYST cells with the papillary-like structure surrounded small blood vessels where inner walls were also covered by malignant cuboidal or columnar cells with the tube-like structure named Schiler-Duval bodies as the most distinctive histological feature. No metastasis was noticed in the liver and lung of tumor-bearing mice.

TYST cells were mainly located between poorly differentiated and undifferentiated state, of which the most exhibited the embryonic or primordial ones, with many glandular-like structures, large nucleus in oval shape, nucleoli prominent, or reduction of intracellular organelles. TYST cells with microvillus structure were partially differentiated into the epithelium-like cells characterized by vacuolar goblet with mucus-like substance. Of TYST cells, some differentiated well were rich in intracellular organelles and nuclei stained deeply, contained desmosomes, or had junction complexes. There were abundant with rod-like crystals, mucus-like substances and ribosomes in differentiated intestinal epithelial cells, which indicated the active proliferation and strong protein synthesis of cells. AFP could be detected outside of cells, which represented the composure of electron dense material as basement membrane material (Figure 1D).

Figure 2 demonstrated the expressions of AFP (A), PLAP (B) and CK (C) in TYST tissue by immunohistochemical staining. Values of average optical density of AFP, PLAP and CK staining at $0.13 \pm 0.08,0.10 \pm 0.06$ and $0.13 \pm 0.07$ ( $\mathrm{n}=90-100$ sections per staining), respectively, were significantly higher than those in the group without primary antibodies $(0.04 \pm 0.01)$. The number of chromosomes with 34-48 and the modal number 46 were consistent with the diploid structure in tumors, different from those of mouse or human (Figure 2D). The breakage or loss was noted in some of chromosomes.

Cloned cells of TYST were passed up to 25 generations with the stable growth and primary characteristics,

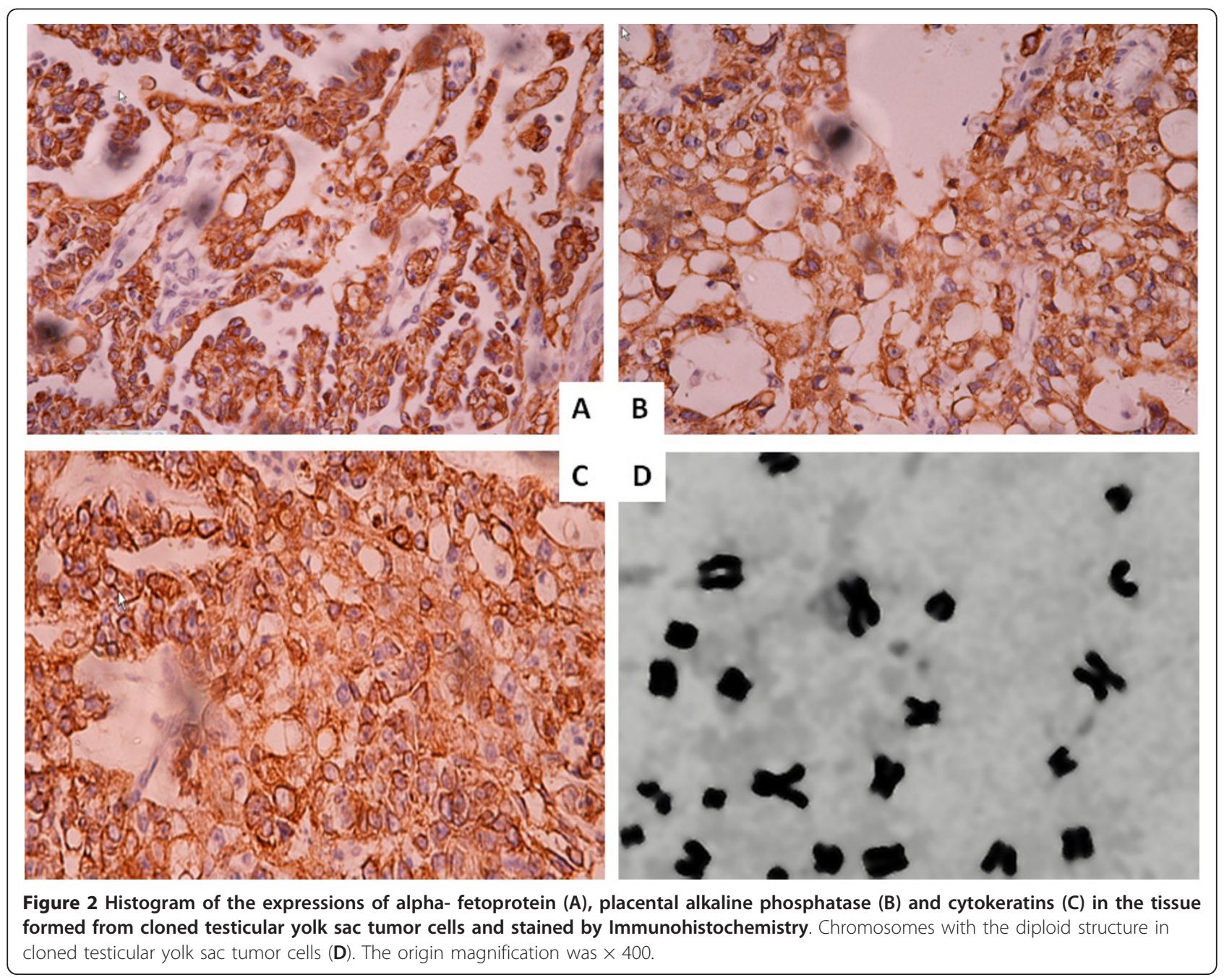


and adhered on the bottom of culture bottle in shapes of short spindle or polygon. Cells lost cell contact inhibition and grew in the bundle toward the certain direction arranged with multiple overlapping growths (Figure 3A). Cells showed obvious heteromorphism and different shapes in size (Figure 3B). Microvilli were noted on the cell surface and the number of rough surfaced endoplasmic reticulum and free ribosome increased, while the number of mitochondria reduced. The nuclear membrane in irregular shapes was edged by decreased heterochromatin (Figure 3c and 3d).

Cloned TYST cell growth curve demonstrated that there was a rapid growth of cells 2-4 days after the culture, followed by a small and consistent growth from 5 days and on (Figure 4A). Proliferation cycle time of cloned cells was about 30 hours, during which cloned cells were doubled. The number of cloned cell chromosomes fluctuated from 39 to 97 , and the modal number was 46. There was no isochromosome of $12 p$, $\mathrm{i}(12 \mathrm{p})$ in G-banding, and some chromosomes in cloned cells had abnormal structures similar to those in the primary TYST cells (Figure 4B). Cloned cells had positive expression of AFP (Figure 4C), rather than $\beta$-hCG (Figure 4D). DNA index of cloned cells was 1.3, as compared with the normal range between 0.9 with 1.1. DNA ploidy analysis showed aneuploidy, and DNA cycle analysis showed that the G0-G1 accounted for $80 \%$ (normal value $80 \%$ ), G2-M for $17.5 \%$ (normal value $10 \%$ ), and $S$ phase for $2.5 \%$ (normal value $10 \%$ ). The purification rate of cloned TYS cells reached about $60 \%$ in the 20th generation cells in double agar for 14 days.

ATRA in the concentrations of $10^{-7} \mathrm{M}$ had significant inhibitory effects on cell proliferation at 48 and 72

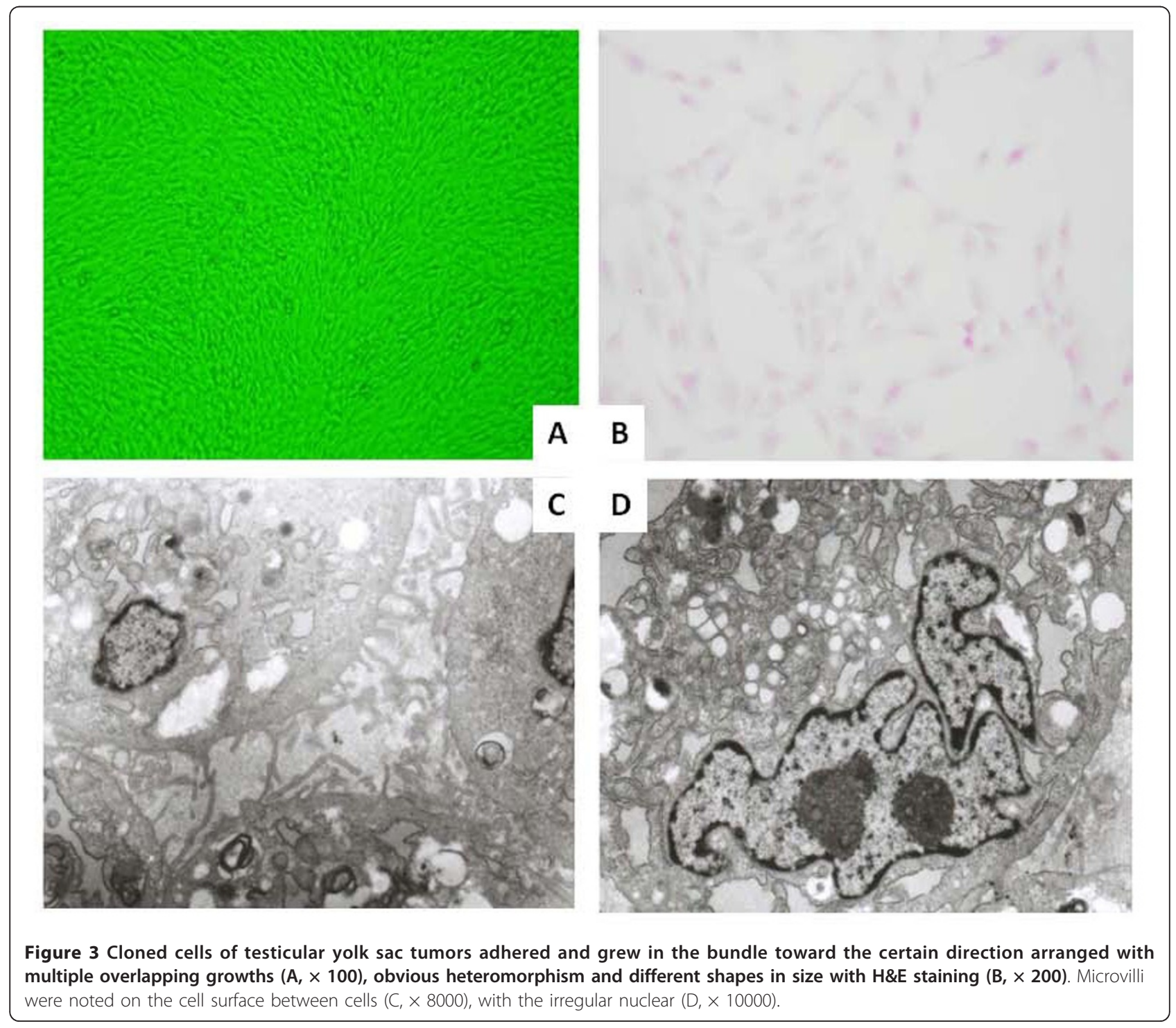




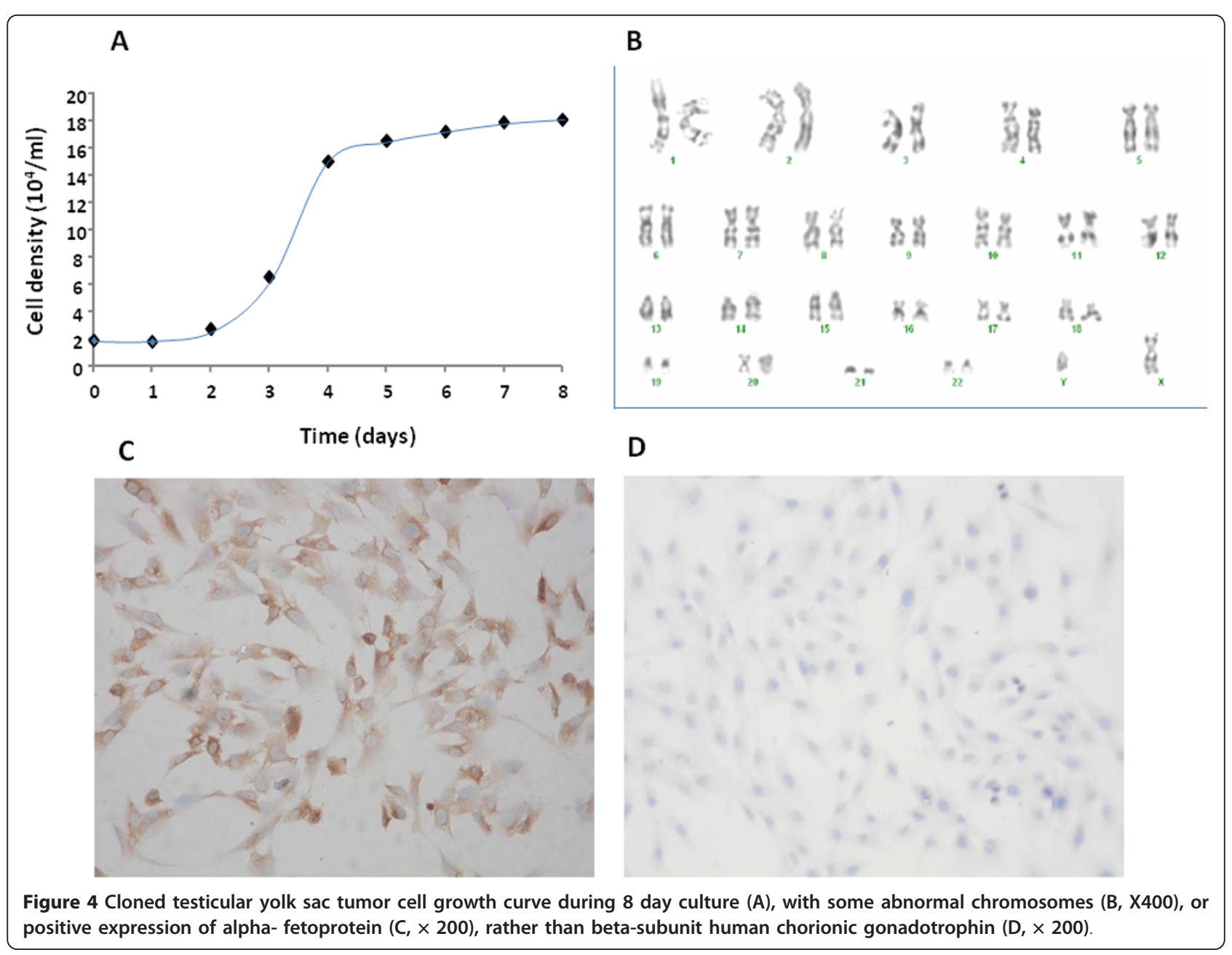

hours (inhibitory rates: 31 and 56\%, respectively, p < 0.05 and 0.01 ), $10^{-6} \mathrm{M}$ at 24,48 and 72 hours (inhibitory rates: 41,53 and $80 \%, \mathrm{p}<0.01$, respectively), or $10^{-5} \mathrm{M}$ at 24, 48 and 72 hours (inhibitory rates: 46, 51 and $81 \%$, $\mathrm{p}<0.01$, respectively), as shown in Figure $5 \mathrm{~A}$. The expression of RAR- $\beta$ mRNA significantly increased from 48 hours and on as well as by time after the treatment with ATPA at concentration of $10^{-6} \mathrm{M}$ (Figure $5 \mathrm{~B}$ ) and with the increased concentrations of ATRA at 48 hours (Figure 5C).

Closed cells used for the measurement of cisplatin effects were AFP-stained positive (Figure 6-A1). Karyopyknosis, nuclei gradually shrank, or apoptotic bodies of apoptotic cells was shown in Figure 6-A2. As compared with those with vehicle (Figure 6-A3), the number of TUNEL-positive cells increased 12 hours after the treatment with cisplatin (Figure 6-A4). Apoptotic index significantly increased $12(14.7 \pm 3.4)$, $24(20.2 \pm 1.6), 48(26.9 \pm 3.4)$ and 72 hours $(34.2 \pm$ 3.6) after the co-culture with cisplatin, as compared with that with vehicle $(6.1 \pm 1.8, \mathrm{p}<0.05$ or 0.01 , respectively). The expression of p53 proteins increased from 12 hours and on after the treatment with cisplantin (Figure 6-B2), while the expression of Bcl-2 proteins decreased and re-distributed from 48 hours (Figure 6-B4), as compared with those with vehicle (Figure 6-B1 and 6-B3). Significance differences of optimal density of p53 and Bcl-2 protein staining were noticed 12 and 24 hours after cisplatin treatment, as shown in Figure 6C and 6D, respectively. There were significantly positive and negative correlations between p53 and apoptotic index $(\mathrm{r}=0.387, \mathrm{P}=0.006)$ and between $\mathrm{Bcl}-2$ and apoptotic index $(\mathrm{r}=-0.888, \mathrm{P}=$ $0.000)$, respectively.

\section{Discussion}

Testicular germ cell tumors account for over $95 \%$ of all testicular neoplasms and the incidence was doubled worldwide over past decades up to $7.5 / 100,000$ [13], while pediatric germ cell tumors account for $60-75 \%$ of pediatric testicular tumors [14], mostly as yolk sac tumor. The in vivo tumor model by the subcutaneous 


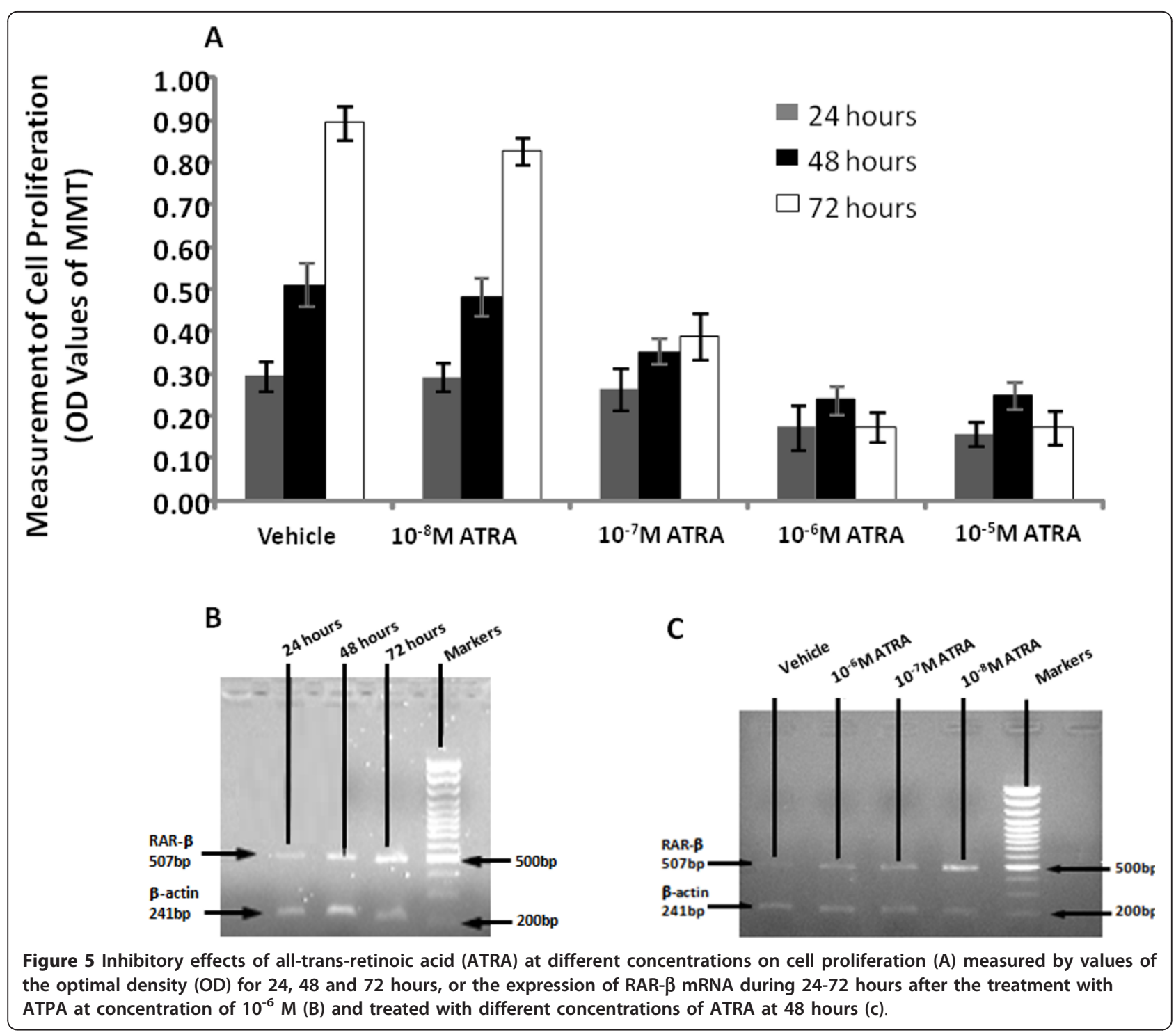

transplantation of tumor cells is accepted due to convenient operation and easy observation [15]. The current study established the TYST model by the passage from the primary TYST cells to the 7th generation in total 95 nude mice during 15 months. The tumor formation rate increased by the development of generations and the average period of tumor formation was about 30 days, similar to pathological characteristics of human TYST [16]. Even though, it is also a challenging to establish the animal model to match the exact schedule and nature of human tumor, which needs more and further investigations. TYST cells were developed into the phase between poorly differentiated and undifferentiated states, with the embryonic or primordial activity. We noted the local differentiation and growth of human TYST cells from the columnar to glandular-like or goblet cells-like cells, while few metastasis in the
TYST model. A number of animal models related to TYST have been investigated and vary among the types and mutations of tumor and its cells, e.g. animal model of human disease based on yolk sac carcinoma (endodermal sinus tumor) (49).

AFP was considered as a mark for the presence of YST, which was initially found in the fetal yolk sac [17], embryonic cells [18] and the gastrointestinal tract [19]. There was a clear correlation between AFP and malignant germ cell tumor [20-23]. AFP was used as a monitoring marker of closed TYST cells and formed in vivo tumor in the resent study. Data from the present study demonstrated that AFP proteins was expressed in isolated primary TYST cells, closed TYST cells, pre-transplanted cells, and formed tumor in animals. In addition, we also noted that TYST cells were positive to PLAP, which was significantly over-expressed on the surface of various solid 


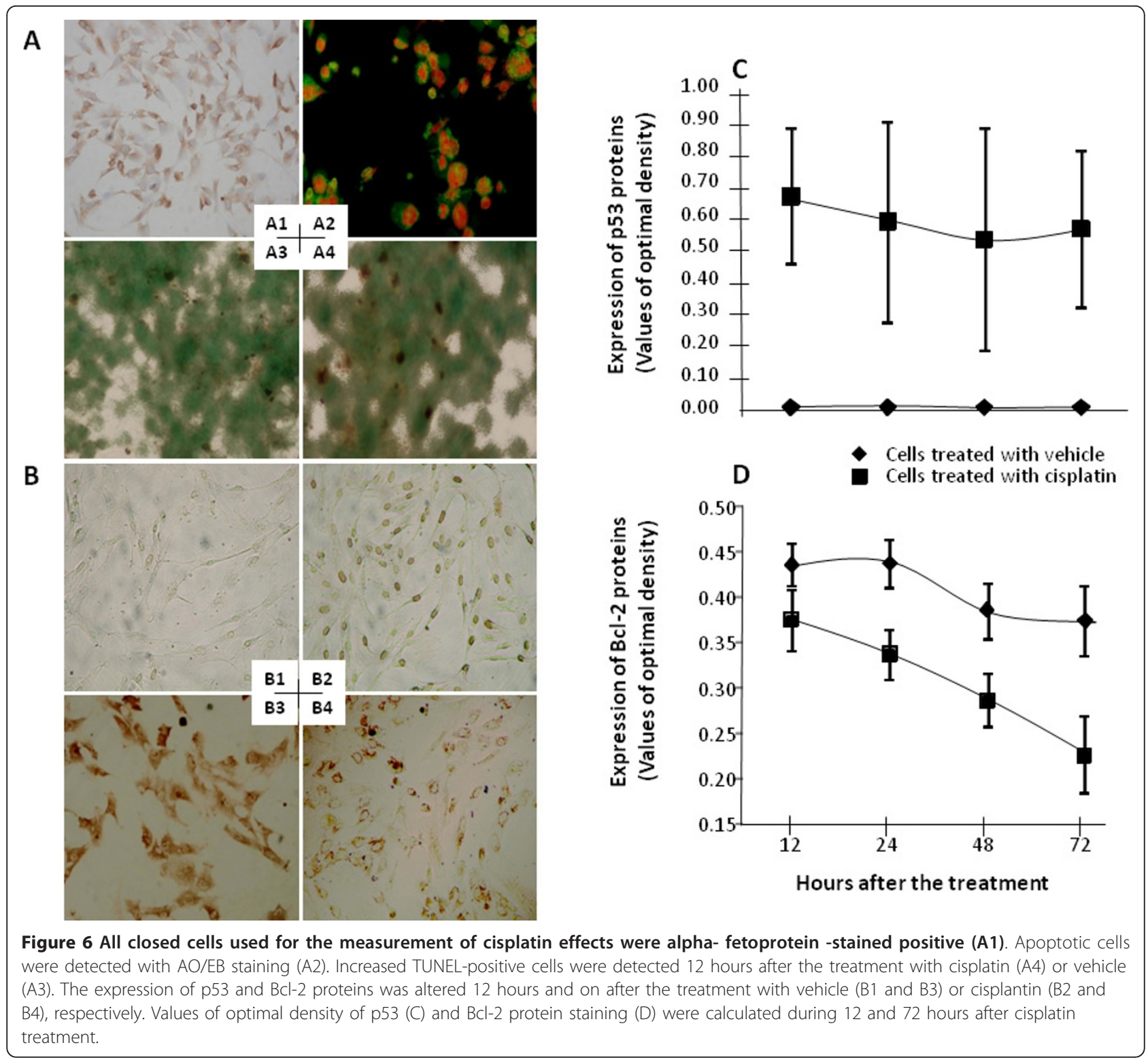

tumor cells [24] and CK as a unique characteristic of tumor cells [25]. PLAP was also considered as a drug design target for non-invasive cancer imaging and therapy [26]. It indicates that the catalysis of the hydrolysis and transphosphorylation of phosphate monoesters is involved in the main metabolism of TYST cells. PLAP, as a classic marker for germ cell tumors through combination of placental membrane glycoprotein with oligosaccharides phosphatidylinositol [24,27], was over-expressed in seminoma, embryonal carcinoma and YST with about $90 \%$ positive rate [28]. We also found that chromosomes for tumor identification in each passage met nature of the primary tumor, as previously reported [29].
We initially cloned and established the TYST cell line confirmed by the histology, ultra-structure, growth kinetics and expression of specific proteins and found biological characteristics of cloned cells were similar to the yolk sac tumor. Cloned cells also represented clear microvilli on cell surfaces up to 25 generations, and possessed strong proliferation. The characteristic cytogenetic abnormality in adult testicular germ cell tumors is the invariable gain of material from chromosome $12 \mathrm{p}$ [30], so called isochromosome $12 p, i(12 p)$, measured by both conventional cytogenetic and molecular cytogenetic techniques, while the abnormal chromosome of $i(12 p)$ hardly occurred in infants [31,32]. Our results on i(12p) 
from the analysis of G-banding were similar to the findings from previous studies [33].

ATRA as natural and synthetic derivatives of vitamin A can bind to the nuclear receptors, involved in the regulation of embryonic development, organogenesis, cell homeostasis, cell growth, differentiation and apoptosis [34-37]. ATRA was used to treat and prevent various types of human cancers and the sensitivity of cancer cells to ATRA was considered as an indicator of the development of ATRA resistance [38]. The cellular sensitivity to ATRA was suggested to be increased upon inactivation of SAG E3 ubiquitin ligase via genetic deletion or pharmacological inhibition [36]. We found that the concentration of ATRA at $10^{-5} \mathrm{M}$ had inhibitory effects of about $50 \%$ on TYST cell proliferation at 24 hours and $10^{-7} \mathrm{M}$ at 72 hours. It seems that TYST cells were more sensitive to ATRA which had significantly inhibitory effects on cell proliferation in the concentrations of $10^{-7} \mathrm{M}$ at 48 hours and $10^{-6} \mathrm{M}$ at 24 hours, as compared with other cells, e.g. peripheral blood mononuclear cells and CD4+ T cells $\left(>10^{-4} \mathrm{M}\right.$ [39]), human A375 melanoma cells $\left(>10^{-5} \mathrm{M}[40]\right)$, breast cancer cells $\left(>>10^{-5} \mathrm{M}[41]\right)$, or small intestinal epithelium $\left(>10^{-5}\right.$ $M$ [42]). The further study is needed to confirm the variation of drug sensitivity between different tumor cells. The binding of ATRA with the receptor leads to alterations of gene expressions, followed by a transport to the nucleus and an activation of ATRA-associated signal transduction [43]. We believe over-expression of ATRA receptors on TYST cells may be responsible for the high sensitivity of TYST cells to ATRA, while the binding of ATRA per se could down-regulate the expression of the receptor.

Cisplatin-based chemotherapy was recently proposed to be an alternative of therapies for patients with germ cell tumors, due to the early vascular toxicity of chemotherapy in the endothelium and production of von Willebrand factors [44]. It was also found that cisplatin might have the direct effects on tumor cell to induce DNA damage and activation of JNK/SAPK pathway [45]. Data from the present study demonstrated that cisplatin induced apoptosis of TYST cells through the activation of p53 expression and down-regulation of Bclexpression. Cisplatin could change the configuration of P53, induce DNA damage, and inhibit cell proliferation by blocking the cell cycle in G1 phase to apoptosis [46]. Cisplatin might change the distribution $\mathrm{Bcl}$ around the nucleus or reduce the connection, transport, or formation of nuclear pore complex, and the maintenance of the nuclear envelope, probably associated with the development of cisplatin resistance in TYST cells $[47,48]$.

In conclusion, we cloned human TYST cells and investigated pathological characteristics of cloned cells in the in vitro and in vivo conditions, confirmed by the histology, ultra-structure, growth kinetics and expression of specific proteins and found biological characteristics of cloned cells were similar to the yolk sac tumor. Human TYST cells could be differentiated from the columnar to glandular-like or goblet cells-like cells. Chromosomes for tumor identification in each passage met nature of the primary tumor. TYST cells were more sensitive to ATRA. Cisplatin induced apoptosis of TYST cells through the activation of p53 expression and down-regulation of Bcl- expression. Thus, we believe that cloned TYST cells and the animal model developed are useful to understand the molecular mechanism of TYST cells and screen new drug candidates for the disease.

\section{Acknowledgements}

We would appreciate the special supports from Wenzhou Medical College and the First Hospital, and "Thousand Talents Program" of the Zhejiang Province.

\section{Author details}

${ }^{1}$ Department of Pediatric Surgery, the Second Hospital, Wenzhou Medical College, Wenzhou, China. ${ }^{2}$ Institute of Translational Medicine, the First Hospital, Wenzhou Medical College, Wenzhou, China. ${ }^{3}$ The First Hospital, Wenzhou Medical College, Wenzhou, China.

\section{Authors' contributions}

JFZ, CDC, HCZ, JHS, HZ, XKL, LQ, XZB, JL and WQL performed and participated in analysis of laboratory experiments data. XMC, XDW, JFZ, CDC, $\mathrm{HCZ}$, JHS participated in the design of experiments. XMC provided administrative support and funded experiments. JFZ, CDC, HCZ, XDW and $X M C$ drafted the manuscript. All authors have read and approved the final manuscript.

\section{Competing interests}

The authors declare that they have no competing interests.

Received: 16 February 2012 Accepted: 13 March 2012 Published: 13 March 2012

\section{References}

1. Travis LB, Beard C, Allan JM, Dahl AA, Feldman DR, Oldenburg J, Daugaard G, Kelly JL, Dolan ME, Hannigan R, Constine LS, Oeffinger KC, Okunieff $P$, Armstrong G, Wiljer D, Miller RC, Gietema JA, van Leeuwen FE, Williams JP, Nichols CR, Einhorn LH, Fossa SD: Testicular cancer survivorship: research strategies and recommendations. J Nat/ Cancer Inst 2010, 102(15):1114-1130.

2. Cao D, Humphrey PA: Yolk sac tumor of the testis. J Urol 2011, 186(4):1475-1476, Epub 2011 Aug 19. No abstract available.

3. Grady RW: Current management of prepubertal yolk sac tumors of the testis. Urol Clin North Am 2000, 27(3):503-508.

4. Brandes AA, Pasetto LM, Monfardini S: The treatment of cranial germ cell tumours. Cancer Treat Rev 2000, 26(4):233-242.

5. Hage-Sleiman R, Herveau S, Matera EL, Laurier JF, Dumontet C: Tubulin binding cofactor $C$ (TBCC) suppresses tumor growth and enhances chemosensitivity in human breast cancer cells. BMC Cancer 2010, 10:135

6. Weaver BA, Cleveland DW: Decoding the links between mitosis, cancer, and chemotherapy: The mitotic checkpoint, adaptation, and cell death. Cancer Cell 2005, 8(1):7-12.

7. Vogelzang NJ, Bronson D, Savino D, Vessella RL, Fraley EF: A human embryonal-yolk sac carcinoma model system in athymic mice. Cancer 1985, 55(11):2584-2593.

8. Shibata K, Kajiyama H, Yamamoto E, Terauchi M, Ino K, Nawa A, Kikkawa F: Establishment and characterization of an ovarian yolk sac tumor cell line 
reveals possible involvement of Nkx2.5 in tumor development. Oncology 2008, 74(1-2):104-111, Epub 2008 Jun 12.

9. Morrison N, Duthie SM, Boyd E, Eidne KA, Connor JM: Assignment of the gene encoding the human thyrotropin-releasing hormone receptor to $8 \mathrm{q} 23$ by fluorescence in situ hybridization. Hum Genet 1994, 93(6):716-718.

10. Craig JM, Bickmore WA: Chromosome bands - flavours to savour. Bioessays 1993, 15:349-354.

11. Oya R, lkemura K: Can flow cytometrically determined DNA ploidy and Sphase fraction predict regional metastasis in squamous cell carcinoma of the oral cavity? Head Neck 2002, 24:136-142.

12. Hedley DW, Clark GM, Cornelisse CJ, Killander D, Kute T, Merkel D: Consensus review of the clinical utility of DNA cytometry in carcinoma of the breast. Report of the DNA Cytometry Consensus Conference. Cytometry 1993, 14(5):482-485.

13. Huyghe E, Plante P, Thonneau PF: Testicular cancer variations in time and space in Europe. Eur Urol 2007, 51(3):621-628.

14. Reuter VE: Origins and molecular biology of testicular germ cell tumors. Mod Pathol 2005, 18(Suppl 2):S51-S60.

15. Jin $H$, Yang Z, Wang J, Zhang S, Sun Y, Ding Y: A superficial colon tumor model involving subcutaneous colon translocation and orthotopic transplantation of green fluorescent protein-expressing human colon tumor. Tumour Biol 2011, 32(2):391-397.

16. Walt $H$, Arrenbrecht $S$, DeLozier-Blanchet CD, Keller PJ, Nauer $R$, Hedinger CE: A human testicular germ cell tumor with borderline histology between seminoma and embryonal carcinoma secreted betahuman chorionic gonadotropin and alpha-fetoprotein only as a xenograft. Cancer 1986, 58(1):139-146.

17. El-Bahrawy M: a-Fetoprotein-Producing Non-Germ Cell Tumors of the Urological System. Rev Urol 2011, 13(1):14-19.

18. Pamies D, Vicente-Salar N, Sogorb MA, Roche E, Reig JA: Specific effect of 5-fluorouracil on alpha-fetoprotein gene expression during the in vitro mouse embryonic stem cell differentiation. Int J Toxicol 2010, 29(3):297-304.

19. Watanabe T, Yamada H, Morimura Y, Abe M, Motoyama T, Sato A: Ovarian Sertoli-Leydig cell tumor with heterologous gastrointestinal epithelium as a source of alpha-fetoprotein: a case report. J Obstet Gynaecol Res 2008, 34(3):418-421.

20. Malati T: Tumour markers: an overview. Indian J Clin Biochem 2007 22:17-31.

21. Kosmehl H, Stadie G, Szöke B, Schulze M: Correlation between the alpha 1 -fetoprotein (AFP) concentrations determined in the sera and in the tumour tissues in patients with testicular tumours. Int Urol Nephrol 1988, 20(2):151-153.

22. Fottner C, Sattarova S, Hoffmann K, Spöttl G, Weber MM: Elevated serum levels of IGF-binding protein 2 in patients with non-seminomatous germ cell cancer: correlation with tumor markers alpha-fetoprotein and human chorionic gonadotropin. Eur J Endocrinol 2008, 159(3):317-327.

23. Borosky GL, Lin S: Computational modeling of the catalytic mechanism of human placental alkaline phosphatase (PLAP). J Chem Inf Model 2011, 51(10):2538-2548.

24. Lee EN, Park JK, Lee JR, Oh SO, Baek SY, Kim BS, Yoon S: Characterization of the expression of cytokeratins 5,8 , and 14 in mouse thymic epithelial cells during thymus regeneration following acute thymic involution. Anat Cell Biol 2011, 44(1):14-24

25. Yang Y, Wang K, Li W, Adelstein SJ, Kassis Al: Human placental alkaline phosphatase-mediated hydrolysis correlates tightly with the electrostatic contribution from tail group. Chem Biol Drug Des 2011, 78(6):923-931

26. Harada T, Koyama I, Sato K, Komoda T: Induction of rat alkaline phosphatase isozymes bearing a glycan-phosphatidylinositol anchor modified by in vivo treatment with a benzimidazole derivative linked to ethylbenzene. Comp Biochem Physiol B Biochem Mol Biol 2000, 127(2):193-202.

27. Ulbright TM: Germ cell tumors of the gonads: a selective review emphasizing problems in differential diagnosis, newly appreciated, and controversial issues. Mod Pathol 2005, 18:S61-S79.

28. Looijenga LH, Gillis AJ, Stoop HJ, Hersmus R, Oosterhuis JW: Chromosomes and expression in human testicular germ-cell tumors: insight into their cell of origin and pathogenesis. Ann N Y Acad Sci 2007, 1120:187-214.
29. McIntyre A, Gilbert D, Goddard N, Looijenga L: Shipley J Genes, chromosomes and the development of testicular germ cell tumors of adolescents and adults. Genes Chromosomes Cancer 2008, 47(7):547-557.

30. Looijenga LH, Zafarana G, Grygalewicz B, Summersgill B, Debiec-Rychter M, Veltman J, Schoenmakers EF, Rodriguez S, Jafer O, Clark J, van Kessel AG, Shipley J, van Gurp RJ, Gillis AJ, Oosterhuis JW: Role of gain of $12 p$ in germ cell tumour development. APMIS 2003, 111(1):161-171.

31. Kato N, Shibuya H, Fukase M, Tamura G, Motoyama T: Involvement of adenomatous polyposis coli (APC) gene in testicular yolk sac tumor of infants. Hum Pathol 2006, 37(1):48-53.

32. Poulos C, Cheng L, Zhang S, Gersell DJ, Ulbright TM: Analysis of ovarian teratomas for isochromosome 12p: evidence supporting a dual histogenetic pathway for teratomatous elements. Mod Pathol 2006, 19(6):766-771.

33. Okuno M, Kojima S, Matsushima-Nishiwaki R, Tsurumi H, Muto Y, et al: Retinoids in cancer chemoprevention. Curr Cancer Drug Targets 2004, 4:285-298

34. Balmer JE, Blomhoff R: Gene expression regulation by retinoic acid. J Lipid Res 2002, 43:1773-1808.

35. Theodosiou M, Laudet V, Schubert M: From carrot to clinic: an overview of the retinoic acid signaling pathway. Cell Mol Life Sci 2010, 67:1423-1445.

36. Tan M, Li Y, Yang R, Xi N, Sun Y: Inactivation of SAG E3 ubiquitin ligase blocks embryonic stem cell differentiation and sensitizes leukemia cells to retinoid acid. PLoS One 2011, 6(11):e27726, Epub 2011 Nov 15.

37. Gupta S, Pramanik D, Mukherjee R, Campbell NR, Elumalai S, de Wilde RF, Hong SM, Goggins MG, De Jesus-Acosta A, Laheru D, Maitra A: Molecular determinants of retinoic Acid sensitivity in pancreatic cancer. Clin Cancer Res 2012, 18(1):280-289.

38. Bidad K, Salehi E, Oraei M, Saboor-Yaraghi AA, Nicknam MH: Effect of alltrans retinoic acid (ATRA) on viability, proliferation, activation and lineage-specific transcription factors of CD4+ T Cells. Iran J Allergy Asthma Immunol 2011, 10(4):243-249.

39. Ishibashi M, Arai M, Tanaka S, Onda K, Hirano T: Antiproliferative and apoptosis-inducing effects of lip ophilic vitamins on human melanoma a375 cells in vitro. Biol Pharm Bull 2012, 35(1):10-17.

40. Czeczuga-Semeniuk E, Lemancewicz D, Wołczyński S: Estradiol and tamoxifen differently affects the inhibitory effects of vitamin A and their metabolites on the proliferation and expression of alpha2beta1 integrins in MCF-7 breast cancer cells. Adv Med Sci 2009, 54(1):91-98.

41. Grenier E, Maupas FS, Beaulieu JF, Seidman E, Delvin E, Sane A, Tremblay E, Garofalo C, Levy E: Effect of retinoic acid on cell proliferation and differentiation as well as on lipid synthesis, lipoprotein secretion, and apolipoprotein biogenesis. Am J Physiol Gastrointest Liver Physiol 2007, 293(6):G1178-G1189.

42. Luo XM, Ross AC: Retinoic acid exerts dual regulatory actions on the expression and nuclear localization of interferon regulatory factor-1. Exp Biol Med (Maywood) 2006, 231(5):619-631.

43. Dieckmann KP, Struss WJ, Budde U: Evidence for acute vascular toxicity of Cisplatin-based chemotherapy in patients with germ cell tumour. Anticancer Res 2011, 31(12):4501-4505.

44. Potapova O, Haghighi A, Bost F, Liu C, Birrer MJ, Gjerset R, Mercola D: The Jun kinase/stress-activated protein kinase pathway functions to regulate DNA repair and inhibition of the pathway sensitizes tumor cells to cisplatin. J Biol Chem 1997, 272(22):14041-14044.

45. Miller RP, Tadagavadi RK, Ramesh G, Reeves WB: Mechanisms of Cisplatin nephrotoxicity. Toxins (Basel) 2010, 2(11):2490-2518.

46. Rudin CM, Yang Z, Schumaker LM, VanderWeele DJ, Newkirk K, Egorin MJ, Zuhowski EG, Cullen KJ: Inhibition of glutathione synthesis reverses Bcl-2mediated cisplatin resistance. Cancer Res 2003, 63(2):312-318.

47. Noel EE, Yeste-Velasco M, Mao XY, Perry J, Kudahetti SC, Li NF, Sharp S, Chaplin T, Xue LY, McIntyre A, et al: The Association of CCND1 Overexpression and Cisplatin Resistance in Testicular Germ Cell Tumors and Other Cancers. Am J Pathol 2010, 176(6):2607-2615.

48. Damjanov I: Animal model of human disease: yolk sac carcinoma (endodermal sinus tumor). Am J Pathol 1980, 98(2):569-572.

doi:10.1186/1479-5876-10-46

Cite this article as: Zhao et al: Evaluation of cloned cells, animal model, and ATRA sensitivity of human testicular yolk sac tumor. Journal of Translational Medicine 2012 10:46. 